\title{
The effect of gastric balloons on weight loss
}

\section{Introduction}

There are around 1.5billion overweight and obese adults around the world. ${ }^{1}$ These adults are in danger of comorbidities such as diabetes, heart disease, stroke and liver disease. ${ }^{2}$ But if these people lose just $10 \%$ of weight, their risk of comorbidities would significantly decrease. These adults can achieve such weight loss with weight loss therapies. There are numerous weight loss therapies, but each has disadvantages. Bariatric surgery is invasive, expensive and dangerous, ${ }^{3}$ while pharmacological methods are relatively ineffective and produce side effects. ${ }^{4}$ Gastric balloons (also known as intra-gastric balloons) are somewhere in-between the two. The gastric balloon procedure consists of placing a silicone balloon in the stomach and then filling it with air or saline. The balloon then floats freely in the stomach for several months. The general purpose is that the balloon reduces the stomach volume and therefore increases satiety. ${ }^{5}$ This literature review will examine the effect of gastric balloons on weight loss. First the review will examine the effectiveness of gastric balloons for weight loss, and then the review will consider hoe permanent the weight loss is. Then the review will examine who is suitable for gastric balloons, and finally his review will consider the method by which gastric balloons cause weight loss.

\section{How effective are gastric balloons for weight loss?}

How much weight do patients lose with gastric balloons? According to a review in 2009 by Dumonceau, patients achieve an average of $18 \mathrm{~kg}$ of weight loss after six months of gastric balloon therapy. ${ }^{6}$ This figure was calculated by averaging the weight loss of 4,877 patients over thirty gastric balloon studies. (A weight loss of $18 \mathrm{~kg}$ corresponds to a BMI reduction of 4 to $9 \mathrm{~kg} / \mathrm{m}^{2}$ ). One particular study followed 130 obese after gastric balloon therapy, and found their weight decreased by $13 \mathrm{~kg}$ after six months of gastric balloon therapy. ${ }^{7}$ Another study of 119 obese patients found the patients lost $12 \mathrm{~kg}$ of body weight on average. ${ }^{8}$ Furthermore, European trials found patients lose $25-40 \%$ of their excess weight after six months. ${ }^{9}$ Other studies also find that gastric balloons do cause significant weight loss, ${ }^{10,11}$ and the amount of weight loss is consistent over studies. ${ }^{1}$

\section{How long does the weight loss last?}

A disadvantage of gastric balloons is that much of the weight loss is only temporary, because patients quickly regain their lost weight after their balloon is removed. ${ }^{12}$ According to Guar et al., ${ }^{1}$ the average patient regains just under half of her lost weight one year after the balloon removal. ${ }^{1}$ The weight loss is more sustained in patients who lose a lot of weight: patients who lose at least $20 \%$ of excess weight sustain about $70 \%$ of the weight loss a year after balloon removal. ${ }^{1}$

The natural question that arises is: why don't patients use gastric balloons permanently? This way, they would never regain their lost weight. The problem is that the longer the balloon is left in the stomach, the higher the chance of side-effects. For this reason, physician almost always remove balloons just six months after insertion, to limit the risk of side effects. Balloons that are left for longer than six months often leak or deflate ${ }^{1}$ and a deflated balloon can block the intestines. There is a balloon called the 'Spatz' which is supposed to last for one year. However, a study found that all the adverse events that occurred
Volume 4 Issue 2 - 2016

\author{
Naif AlEnazi \\ Department of surgery, Prince Mohammed bin abdulaziz \\ hospital, Saudi Arabia
}

Correspondence: Naif AIEnazi, Consultant Bariatric \&Metabolic surgery, Department of surgery, Prince Mohammed bin abdulaziz hospital, Ministry of health, Riyadh - kingdom of Saudi Arabia, Email Surgeon_n@hotmail.com

Received: December 07, 2015 | Published: February 18, 2016

during Spatz balloon therapy occurred after six months of operation. ${ }^{13}$ This implies that the Spatz is safe for before six months of insertion, but becomes dangerous after six months.

\section{Who is suitable for gastric balloons?}

Firstly, gastric balloons are unsuitable for people with a BMI less than $27,{ }^{3}$ because the risks of the balloons outweigh the benefits. Patients who are most suitable have starting BMIs of $30-40 \mathrm{~kg} / \mathrm{m}^{2}$, because these patients lose the most weight with gastric balloons. ${ }^{6}$ However, gastric balloons is also useful for morbidly obese patients (patients with BMIs greater than 45 , because it can help them to lose weight for surgery. ${ }^{6}$ These patients have to lose weight for surgery because their current weight makes surgery too dangerous. If they did go into surgery, then they would be at a high risk of complications such as infections, blood clots and slow healing of wounds. So, therefore gastric balloons are useful as the first stage of a multi-stage procedure, since they can help patients lose enough weight until surgery is a safe option. Unlike surgery, gastric balloons are not too dangerous for morbidly obese people, because they are easy to insert and remove.

Gastric balloons are also suitable for unsuccessful dieters, because they are more effective than dieting. They are also more effective and cause less side effects than weight loss medication. ${ }^{1}$ Gastric balloons fall in the middle of the weight loss spectrum, because they are more effective than drugs and dieting but less effective than surgery, but they are also less invasive than surgery but more invasive than dieting and drugs. So essentially, gastric balloons are suitable for patients who need something more effective than dieting and medication but less invasive than surgery.

\section{How do gastric balloons cause weight loss?}

The precise mechanism by which gastric balloons cause weight loss is unknown. It is thought that the balloon's weight stimulates baroceptors in the gastric wall, which in turn stimulates satiety. Though it is also thought that the balloons increase satiety via decreased ghrelin secretion. Ghrelin is a neuro peptide that increases hunger, so if gastric balloons decrease ghrelin secretion, then this is turn would decrease hunger. Although some studies $d$ find that gastric balloons decrease ghrelin levels, other studies find that ghrelin levels remains unchanged. ${ }^{14,15}$

Another theory is that gastric balloons cause weight loss by delaying gastric emptying. ${ }^{14}$ Delayed gastric emptying means that 
food stays in the stomach for longer. This could cause weight loss because a full stomach sends satiety signals to the brain to tell the person to stop eating. The ability of gastric balloons to delay gastric emptying is also unknown. It could be due to the balloon's effect on the gastric wall, or due to changes in ghrelin and leptin levels. We do know that gastric emptying time slows during the first three months after the operation, then quickens in the next three months, and then finally returns to normal after the physician removes the balloon. ${ }^{16,17}$ This could explain why $80 \%$ of weight loss occurs during the first three months of balloon therapy. ${ }^{1}$

\section{Conclusion}

Gastric balloons do not cause a great deal of weight loss and are ineffective in the long term. Patients typically lost about $18 \mathrm{~kg}$ of weight after six months, but then regain $9 \mathrm{~kg}$ a year after the balloon is removed. Gastric balloons are useful for morbidly obese people who need to lose weight before they can start surgery. They are also suitable for people who do not want to undergo an invasive surgical operation. In all, gastric balloons are only a short-term solution to obesity, but they are the best solution when other options are ineffective or unavailable.

\section{Acknowledgements}

None.

\section{Conflict of interest}

The author declares no conflict of interest.

\section{References}

1. Gaur S, Levy S, Mathus Vliegen L, et al. Balancing risk and reward: a critical review of the intragastric balloon for weight loss. Gastrointest Endosc. 2015;81(6):1330-1336.

2. National Collaborating Centre for Primary Care. Obesity: Guidance on the prevention, identification, assessment and management of overweight and obesity in adults and children. UK: National Institute for Clinical Excellence; 2006.

3. Mathus Vliegen EM. Endoscopic treatment: the past, the present and the future. Best Pract Res Clin Gastroenterol. 2014;28(4):685-702.

4. Ling H, Lenz TL, Burns TL, et al. Reducing the risk of obesity: defining the role of weight loss drugs. Pharmacotherapy. 2013;33(12):13081321 .
5. Genco A, Roberta M, Massimiliano C, et al. Endoscopic Treatment: Intragastric Balloon. In: Lucchese M, Scopinaro N, editors. Minimally Invasive Bariatric and Metabolic Surgery. Springer International Publishing; 2015. p. 145-152.

6. Dumonceau JM. Evidence-based review of the Bioenterics intragastric balloon for weight loss. Obes Surg. 2008;18(12):1611-1617.

7. Forlano R, Ippolito AM, Iacobellis A, et al. Effect of the BioEnterics intragastric balloon on weight, insulin resistance, and liver steatosis in obese patients. Gastrointest Endosc. 2010;71(6):927-933.

8. Mui WL, Ng EK, Tsung BY, et al. Impact on obesity-related illnesses and quality of life following intragastric balloon. Obes Surg. 2010;20(8):1128-1132.

9. Korner J, Nandi A, Wright SM, et al. Implantable gastric stimulator does not prevent the increase in plasma ghrelin levels that occurs with weight loss. Obesity. 2011;19(10):1935-1939.

10. Totté E, Hendrickx L, Pauwels M, et al. Weight reduction by means of intragastric device: experience with the bioenterics intragastric balloon. Obes Surg. 2001;11(4):519-523.

11. Alfalah $\mathrm{H}$, Philippe $B$, Ghazal F, et al. Intragastric balloon for preoperative weight reduction in candidates for laparoscopic gastric bypass with massive obesity. Obes Surg. 2006;16(2):147-150.

12. Caglar E, Dobrucali A, Bal K. Gastric balloon to treat obesity: filled with air or fluid? Dig Endosc. 2013;25(5):502-507.

13. Kannan RY, Nutt MR. Are intra-gastric adjustable balloon system safe? A case series. Int J Surg Case Rep. 2013;4(10):936-938.

14. Mion F, Napoléon B, Roman S, et al. Effects of intragastric balloon on gastric emptying and plasma ghrelin levels in non-morbid obese patients. Obes Surg. 2005;15(4):510-516.

15. Mathus Vliegen EM, Eichenberger RI. Fasting and meal-suppressed ghrelin levels before and after intragastric balloons and balloon-induced weight loss. Obes Surg. 2014;24(1):85-94.

16. Bonazzi P, Petrelli MD, Lorenzini I, et al. Gastric emptying and intragastric balloon in obese patients. Eur Rev Med Pharmacol Sci. 2005;9(Suppl 1):15-21.

17. $\mathrm{Su} \mathrm{HJ}, \mathrm{Kao} \mathrm{CH}$, Chen WC, et al. Effect of intragastric balloon on gastric emptying time in humans for weight control. Clin Nucl Med. 2013;38(11):863-868. 